Supporting Information for

\title{
Functionalized Polybutadiene for Clay/Polymer Nanocomposite Fabrication
}

Vijesh A. Tanna ${ }^{1}$, Joshua S. Enokida ${ }^{1}$ E. Bryan Coughlin ${ }^{1}$ H. Henning Winter ${ }^{1,2 *}$

${ }^{1}$ Department of Polymer Science and Engineering, University of Massachusetts Amherst

${ }^{2}$ Department of Chemical Engineering, University of Massachusetts Amherst

* Corresponding Author Contact

H. Henning Winter

winter@umass.edu

413-545-0922

The ${ }^{1} \mathrm{H}$ NMR spectra of the polybutadienes at increasing grafting densities is shown in Figure S1. Specifically, the ratio of alpha to the grafted hydroxyl group (marked by the arrow) with respect to the unreacted double bonds was calculated to tabulate this value. GPC traces of the same polymers are plotted in Figure S2. A slight change in dispersity is observed and potential reasons have been addressed in the discussion section. 


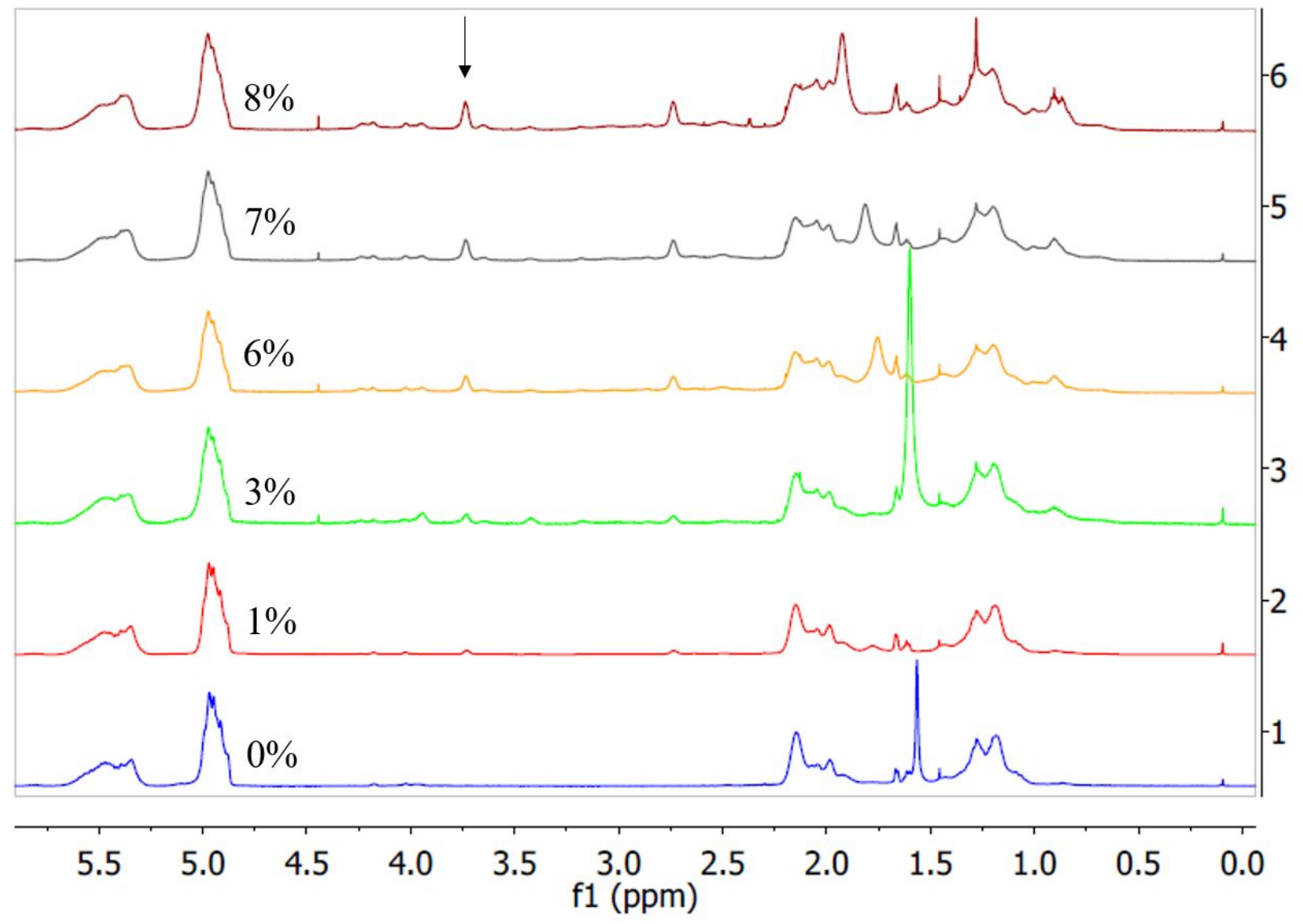

Figure S1: Proton NMR used to quantify the grafting density after thiol-ene click chemistry was performed.

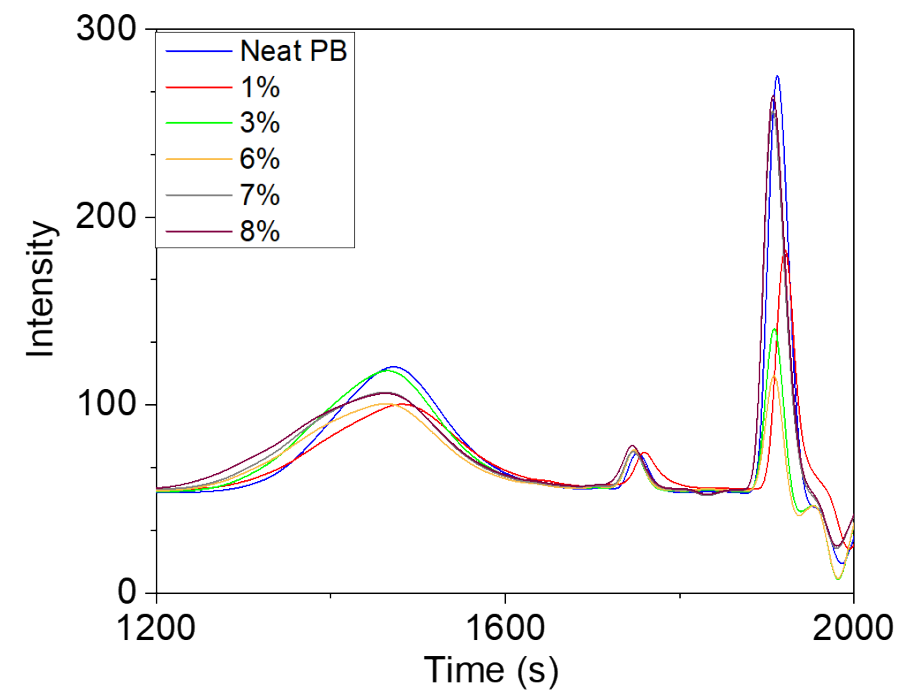

\begin{tabular}{|c|c|c|c|}
\hline $\begin{array}{l}\text { Vinyl } \\
\text { converted/ } \\
\text { Initial } \\
\text { vinyl }^{\mathbf{b}}(\%)\end{array}$ & $\begin{array}{l}\mathbf{M}_{\mathrm{n}} \\
\text { (g/mol) } \\
\text { PMMA } \\
\text { Standard }\end{array}$ & $\begin{array}{l}\mathrm{M}_{\mathrm{w}} \\
\text { (g/mol) } \\
\text { PMMA } \\
\text { Standard }\end{array}$ & PDI \\
\hline 0 & 5,000 & 7,850 & 1.57 \\
\hline 1 & 5,100 & 9,231 & 1.81 \\
\hline 3 & 5,500 & 9,405 & 1.71 \\
\hline 6 & 5,900 & 10,679 & 1.81 \\
\hline 7 & 5,900 & 10,679 & 1.81 \\
\hline 8 & 6,100 & 12,261 & 2.01 \\
\hline
\end{tabular}

Figure S2: THF GPC traces of the reacted polybutadienes. 
The shift factor and relaxation spectra of the grafted polymers before the addition of clay (Figure 3a). The shift factors follow the WLF fit nicely seen by the line fits in the Figure S3a. In addition, systemic increases in the polymers relaxation times occur with increasing grafting density due to the increase in interchain interactions.
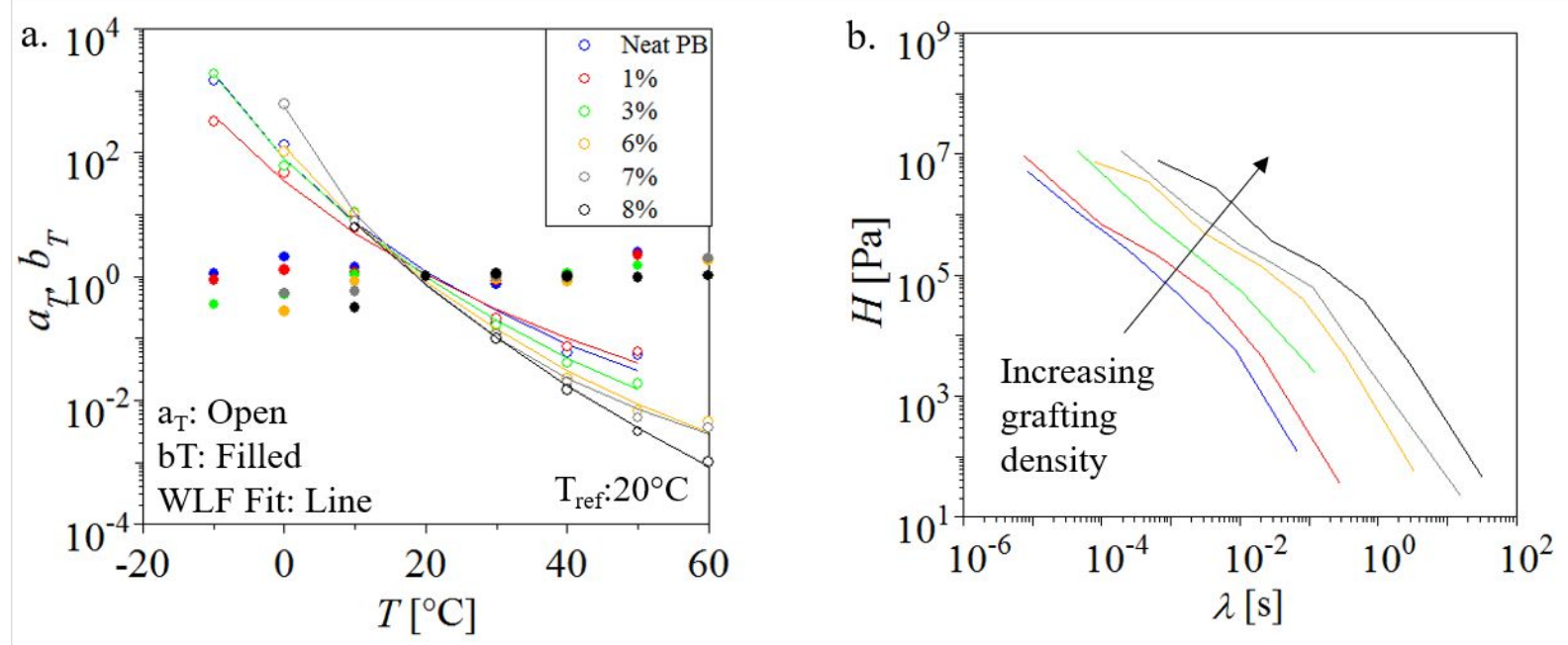

Figure S3: Shift factors and WLF fit of the grafted polymers (Figure S3a) and the characterization relaxation of the grafted polymers (Figure S3b).

As a reference Figure S4, compares the master curve of neat PB with and without clay. This experimental verifies that the increased in modulus requires the hydroxyl groups to be present.

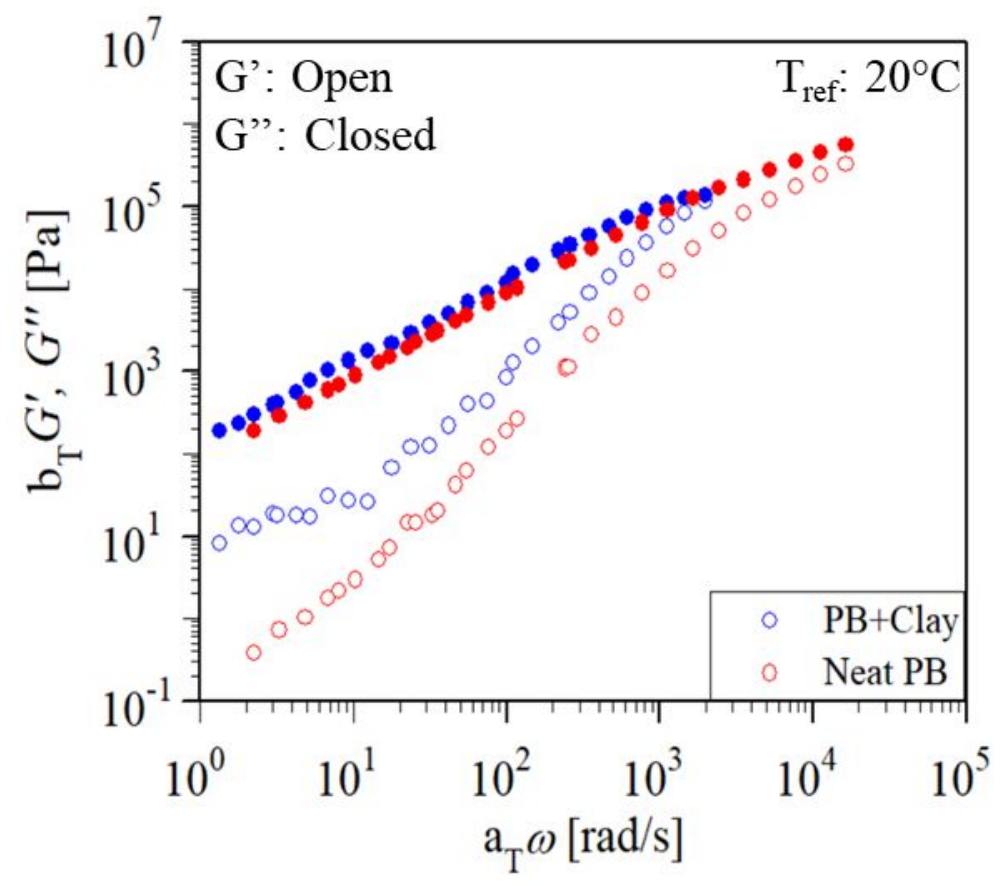

Figure S4: Master curves of neat PB with and without clay. 